\title{
Oil recovery and wettability alteration in carbonates due to carbonate water injection
}

\author{
E. M. Ruidiaz ${ }^{1}$ A. Winter ${ }^{1} \cdot$ O. V. Trevisan ${ }^{2}$
}

Received: 5 May 2016/Accepted: 10 April 2017/Published online: 27 April 2017

(c) The Author(s) 2017. This article is an open access publication

\begin{abstract}
Enhanced oil recovery in carbonates due to wettability alteration has received much attention recently. In contrast to sandstones reservoirs, carbonates are neutralwet or preferentially oil-wet. The use of $\mathrm{CO}_{2}$ dissolved into water has emerged as an alternative method for EOR operations in carbonates reservoirs. In the present paper, oil recovery from two carbonate outcrop rocks was evaluated with different brines containing $\mathrm{CO}_{2}$. The evaluation included a qualitative approach by spontaneous imbibition tests and a quantitative assessment by the Amott-Harvey index. The rocks tested were limestone and dolomite samples known as analogous to Brazilian pre-salt reservoirs. The testing fluids were a medium gravity crude oil, seawater concentration brine, formation equivalent brine and the carbonated version of these brines. Results shown additional oil recovery directly associated with wettability alteration driven by brine concentration switches. Oil recovery increases were observed independently if the brine concentration decreased or increased over the water replacement process. Wettability alteration took place in both carbonate types starting at oil-wet to neutral-wet conditions. Similar tests carried out with equivalent carbonated brines showed similar alterations in the wetting properties, trending no dependence on salt concentration. However, $\mathrm{CO}_{2}$ and its derived ions dissolved in the brines seem to inhibit the wettability alteration mechanism.
\end{abstract}

E. M. Ruidiaz

eddy@ cepetro.unicamp.br

1 Center of Petroleum Studies, CEPETRO/Unicamp, Campinas, São Paulo, Brazil

2 Petroleum Engineering Division, State University of Campinas, Campinas, São Paulo, Brazil
Keywords Spontaneous imbibition - Oil recovery · Wettability alteration - Carbonate water - Amott-Harvey index

\begin{tabular}{ll}
\multicolumn{2}{l}{ List of symbols } \\
$\varphi$ & Porosity \\
$\kappa$ & Permeability \\
$S_{\mathrm{wi}}$ & Irreducible water saturation \\
$\mathrm{cP}$ & Centipoise \\
$I_{\mathrm{A} \_\mathrm{H}}$ & Amott-Harvey wettability index \\
{$\left[\mathrm{S}_{\mathrm{CO}_{2}}\right]_{35 \mathrm{kppm}}$} & Solubility of $\mathrm{CO}_{2}$ in seawater \\
{$\left[\mathrm{S}_{\mathrm{CO}_{2}}\right]_{200 \mathrm{kppm}}$} & Solubility of $\mathrm{CO}_{2}$ in formation water \\
$\mathrm{SW}$ & Seawater concentration \\
$\mathrm{FW}$ & Formation water concentration \\
$\mathrm{CSW}$ & Carbonated seawater \\
$\mathrm{CFW}$ & Carbonated formation water
\end{tabular}

\section{Introduction}

The most widely used technique to obtain additional oil recovery from offshore reservoirs is the injection of seawater or a mixture between seawater and formation water. The technique lines up the proved practice used for pressure support with the purpose of reducing both facility requirements and environmental impacts. Such brine mixing was the field practice calling the attention to the theme of injection water composition. The impact of water salinity and ion composition on oil recovery from carbonate reservoirs has been an area of active research in recent years (Shehata et al. 2014; Yousef and Ayirala 2014; Al-Attar et al. 2013). 
Carbonated seawater injection (CWI) as an EOR method has become more interesting in offshore fields with access to $\mathrm{CO}_{2}$ as well as in cases in which the crude oil has an important amount of $\mathrm{CO}_{2}$ in the associated gas. The technique has been shown to be more efficient than conventional $\mathrm{CO}_{2}$ flooding (Kechut et al. 2010; Fjelde and Asen 2010). The advantages can result in an opportunity to enhance oil recovery and to reduce $\mathrm{CO}_{2}$ emissions and discharges to the environment at the same time. However, there are limited experimental data showing the advantage of use CWI as EOR method in carbonates.

One of the main parameters to be analyzed is the wettability of the reservoir rocks and the possibility of its alteration. Wettability states have a direct relation to fluid distribution in the rock and to the flow of fluids across paths in the reservoir. Carbonates usually present high levels of heterogeneity and are preferentially oil-wet. A smart move in the situation is to modify the rock preference which means changing the rock surface to be more on the water-wet side. Rock wettability can be assessed by several techniques and indexes. In the lab duties, static spontaneous imbibition experiments (Høgnesen et al. 2006; Karimaie et al. 2006; Schembre et al. 2006) and qualitative indicators combining with different core flooding tests which render quantitative indexes for wettability. Such indexes vary with the physicochemical properties of the fluids used (Alotaibi and Nars-El-Din 2009; Al-Maamari and Buckley 2000) and the rock properties.

Spontaneous imbibition tests are the most used of the techniques for prime characterization of rock wetting. Several authors (Schembre et al. 2006; Alotaibi and NarsEl-Din 2009; Standnes and Austad 2000) have carried out experiments in order to study the drive mechanism for oil recovery from different carbonate rocks and wettability conditions.

Quantitative measurements of wettability have been investigated over original core material (reservoir rocks) and outcrop rocks (analogous reservoir models). In both cases, the rock samples need to be restored to the original wettability of the reservoir. This procedure consists in proper cleaning, drying and preparing for initial water saturation, followed by an aging course. Different techniques can be used, and several setups for wettability restoration may render the needed pre-condition for forced displacement tests (Karimaie et al. 2006).

Wettability alteration studies on carbonates (Liu et al. 2007; Zhang et al. 2007) showed the potential of altering the wetting properties by modifying the chemical composition of the injected water. Some authors call "smart water" the water modified with such purpose, pointing to the ions that present more potential to provoke the effect (Zhang et al. 2007; Strand et al. 2006; Zhang and Austad 2006). The wettability change appears to depend on the nature of the rock surface affinity to the oil polar compounds which turned the rock more oil-wetting. After the surface preference to oil, the potential determining ions can be adsorbed at the surface dislodging the polar components and rendering a more water-wet surface. Nonetheless, there is limited work published on wettability alteration of carbonate rocks as a consequence of carbonated water injection. The present work focuses on wettability alteration of carbonate outcrop rocks that is analogous to Brazilian presalt reservoirs. The effect on wetting properties is sought after injecting brines of different salt concentrations with and without dissolved $\mathrm{CO}_{2}$. The Amott-Harvey wettability index is used as indicator of the changes in the wetting properties along the fluid injection and fluid replacements.

\section{Materials and methods}

\section{Rock samples}

The carbonate rocks tested were of dolomite and limestone types. The dolomite cores were extracted from the Silurian Devonian formation, Pennsylvania, USA. The limestone cores were extracted from the Morro do Chaves formation found at the Sergipe-Alagoas Basin, Brazil. These carbonates present properties that are similar to the reservoir rocks of the Brazilian pre-salt. The rock cores were properly cleaned, dried and measured the basic petrophysical properties. These properties ranged between 7 and $21 \%$ for porosity and from 10 to $400 \mathrm{mD}$ in absolute permeability. The dimensions and properties of the samples are listed in Table 1.

\section{Crude oil}

Crude oil from a Brazilian pre-salt reservoir was used in the study. The oil carried the following properties: density of $28^{\circ}$ API and viscosity of $6.4 \mathrm{cP}$ at reservoir temperature $\left(>60{ }^{\circ} \mathrm{C}\right)$. The crude was used in its original condition to age the samples. Due to the observed interaction between the carbonate brine and the original crude, derived oil was prepared by des-asphalting (ASTM D6560-05) and dewaxing (ASTM D2007-11) the original oil for use in the displacement runs involving CWI.

\section{Brine concentrations}

The experiments were carried out with synthetics of the formation brine and seawater, and their carbon dioxidesaturated versions. The synthetic brines were prepared with $100 \%$ of $\mathrm{NaCl}$ dissolved in distilled and de-ionized water. The seawater $(\mathrm{SW})$ and formation water $(\mathrm{FW})$ equivalent concentrations were 35,000 and 200,000 ppm, 
Table 1 Rock properties

\begin{tabular}{rcll}
\hline & $\varphi(\%)$ & $\kappa(\mathrm{mD})$ & Diameter length $(\mathrm{mm})$ \\
\hline Dol & & & \\
D0 & 14.5 & 265 & $37.7 / 58.0$ \\
D1 & 7.7 & 11 & $37.9 / 62.5$ \\
D2 & 7.98 & 11.2 & $37.9 / 62.3$ \\
D6 & 17.8 & 558 & $36.9 / 59.1$ \\
D3 & 17.5 & 94.1 & $37.7 / 59.4$ \\
D4 & 13.3 & 93.6 & $37.7 / 59.5$ \\
D5 & 13.8 & 144 & $37.7 / 62.7$ \\
D7 & 17.5 & 94.1 & $37.6 / 59.4$ \\
Lim & & & \\
C0 & 10.03 & 152 & $37.6 / 65.8$ \\
C1 & 15.5 & 276 & $37.5 / 62.4$ \\
C2 & 14.9 & 278 & $37.5 / 62.1$ \\
C6 & 21.1 & 279 & $37.7 / 59.6$ \\
C3 & 20.2 & 381 & $37.7 / 59.9$ \\
C4 & 20.4 & 372 & $37.5 / 59.6$ \\
C5 & 10.25 & 42.6 & $37.5 / 61.9$ \\
C7 & 18.1 & 372 & $37.5 / 59.6$ \\
\hline
\end{tabular}

Table 2 Solubility of carbon dioxide in SW and FW brines

\begin{tabular}{ll}
\hline$\left[S_{\mathrm{CO}_{2}}\right]_{\mathrm{SW}}(\mathrm{CSW})$ & $0.7826 \mathrm{~mol} / \mathrm{kg} \mathrm{s} / \mathrm{n}$ \\
{$\left[S_{\mathrm{CO}_{2}}\right]_{\mathrm{FW}}(\mathrm{CFW})$} & $0.4880 \mathrm{~mol} / \mathrm{kg} \mathrm{s} / \mathrm{n}$ \\
\hline
\end{tabular}

respectively. The carbonated brines were obtained by dissolving the proper amount of $\mathrm{CO}_{2}$ in the brine at working pressure. The amount of $\mathrm{CO}_{2}$ to be dissolved was determined according to the different salt concentrations (Duan and Sun 2003). For these tests, $\mathrm{CO}_{2}$ was dissolved in both brines (CSW and CFW) at 2000 psi and the calculated solubilities for seawater and reservoir water are shown in Table 2.

\section{Saturation and aging}

The rock cores were cleaned with distilled water and dried at $80{ }^{\circ} \mathrm{C}$ until reaching constant weight, then evacuated down to $1.0^{-3}$ mbar for $16 \mathrm{~h}$. After that, the saturation fluid (crude oil for the spontaneous imbibition tests and FW in the preparation for the displacement tests at irreducible water saturation) was admitted to the vessel and pressurized by an injection pump up to 2000 psi. The vessel remained at this condition for $24 \mathrm{~h}$ to ensure complete saturation of the samples.

In order to achieve irreducible water saturation $\left(S_{\mathrm{wi}}\right)$ in preparation for the displacement tests, the water-saturated rocks were arranged one at a time in a coreholder and flooded at least with 10 pore volumes of oil. Then, each rock was immersed in individual beakers with crude oil and placed in an oven at $90{ }^{\circ} \mathrm{C}$ to age for 1000 and $2500 \mathrm{~h}$ for the spontaneous imbibition tests. For the Amott-Harvey wettability runs, the cores were aged $2500 \mathrm{~h}$.

\section{Spontaneous imbibition tests at low and high pressure}

Two different setups were used in the spontaneous imbibition tests: a standard Amott cell for the lowpressure runs using brine and a high-pressure Amott cell for the carbonated brine runs (Fig. 1). After aging, the excess oil was removed from the surface of each core. Each sample was placed in an individual Amott cell with SW or FW, depending on the test. Then, all cells were settled in an oven at $64{ }^{\circ} \mathrm{C}$ and the oil production was monitored. After securing that no more oil was produced, the imbibing fluid was switched to a new one, with a different concentration. The procedure consisted of alternating the brine concentrations, i.e., cells initially evaluated with SW were switched to FW and vice versa. The procedure was carried on with all rocks and repeated three times.

\section{Amott-Harvey wettability index}

For the Amott-Harvey tests, rock cores were previously prepared at irreducible water saturation and aged for $2500 \mathrm{~h}$. The experimental setup shown in Fig. 2 is an unsteady-state oil recovery apparatus. The setup consists of a positive displacement pump (by DBR) connected to a series of three pressurized vessels containing, respectively, oil, FW and SW, the coreholder and the collecting system. The test started at the irreducible oil saturation condition $\left(S_{\text {or }}\right)$ and was carried out in four steps in order to evaluate the Amott-Harvey wettability index: The steps correspond to the processes of natural imbibition in oil, forced displacement with oil, natural imbibition in brine and forced displacement with brine. At each step, the volumes were collected and measured to furnish the index calculation. After the first round of evaluation (round 1), the rocks were subjected to a second full wettability index evaluation (round 2) using the switched brine. Finally, the rocks were again evaluated with the initial brine (round 3 ).

\section{Amott-Harvey wettability index with carbonate water}

For the evaluation of the Amott-Harvey index with carbonated water, the derived oil was used instead of the original crude. An adaptation of the coreholder was required in order to proceed with the spontaneous 
Fig. 1 Experimental setup for spontaneous imbibition at high and low pressure, a lowpressure cell and $\mathbf{b}$ pressurized cell
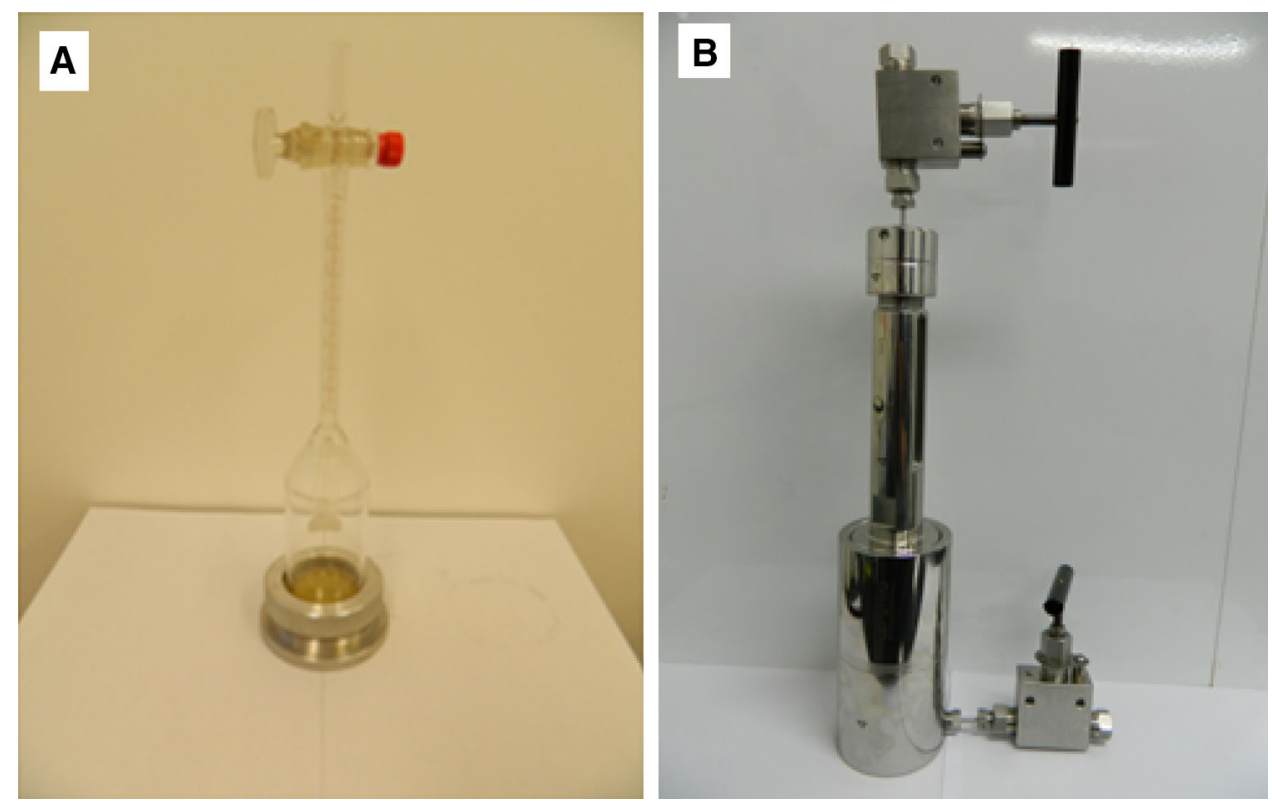

Fig. 2 Experimental setup for the Amott-Harvey wettability tests

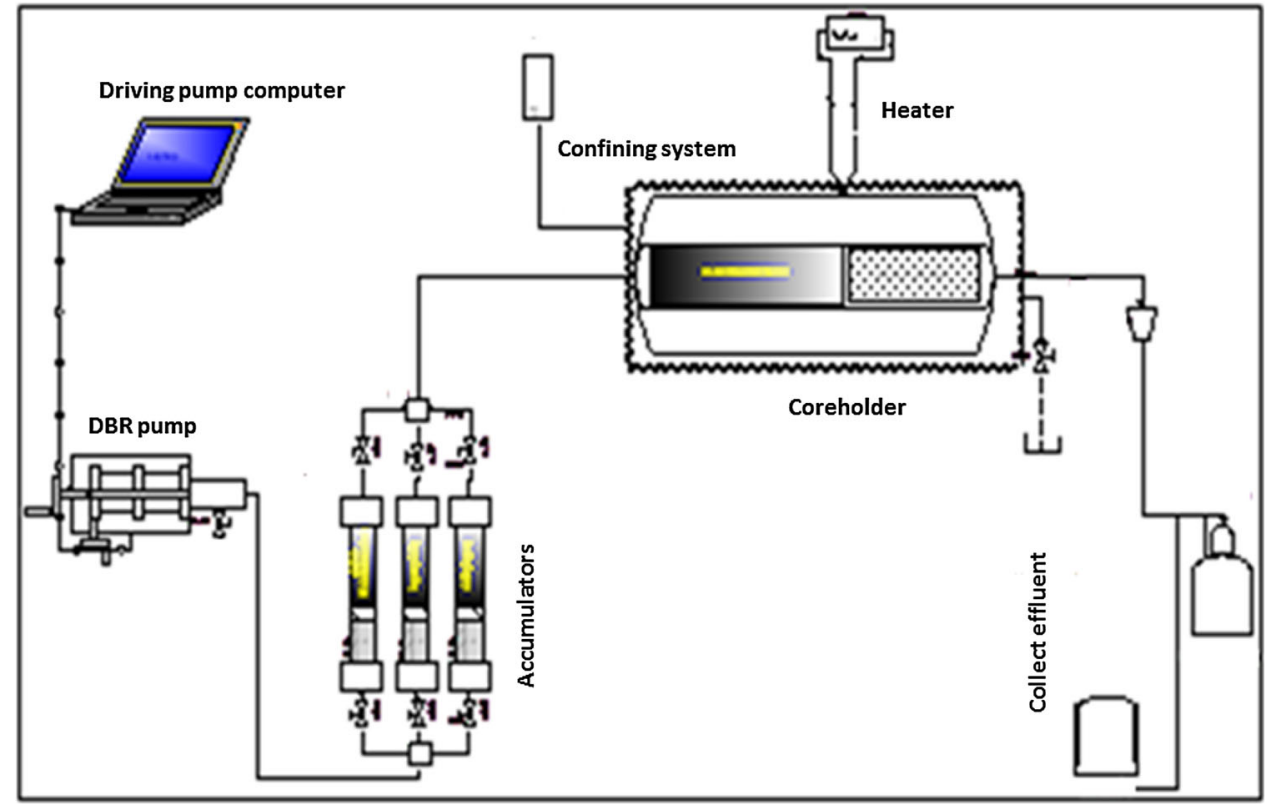

imbibition test under pressure. The adaptation consisted of placing an aluminum ring assembled inside the coreholder as shown in Fig. 3. The ring provides volume to receive the fluid necessary to carry the imbibition test in the sequence. Depressurization would take place in the coreholder, and subsequent desorption of gas would occur while taking the sample from the spontaneous imbibition setup to the displacement arrangement, if the test were done by the traditional procedure and apparatus. Except that, the remaining of the procedure for evaluating the wettability index was kept the same, including the rounds of changes in brine concentration.

\section{Results}

\section{Oil recovery by spontaneous imbibition with water}

After aging the crude oil for 1000 and $2500 \mathrm{~h}$, oil recovery tests were carried out by spontaneous imbibition using seawater and formation water as imbibition fluids. Figures 4 and 5 show the volume of oil produced against time for the limestone and dolomite samples, respectively. For the limestone, the volume of oil recovered reached a plateau for the two aging conditions applied. The first observation is that $1000 \mathrm{~h}$ was enough for the adsorption of the 
oil polar compounds by the rock surface. The second is that, for the cores and conditions used, the brine concentration does not play a significant role in oil recovery, given the similar ultimate recovery efficiency in all tests.

The dolomite cores were evaluated at the same conditions used with the limestone cores. Figure 5 shows the evolution of oil recovery in these cores. Distinctly from the results with limestone, the amount of oil recovered decreases with the increase in aging time. For the short aging time, oil recoveries were $12.7 \%$ of OOIP using SW and $16.6 \%$ OOIP with FW. In contrast, for the long aging time they were 4.8 and $6.2 \%$ with SW and FW, respectively. This is a clear indication of a less reactive surface toward the polar compound adsorption. The 1000-h aging time was not enough to turn the dolomite samples into a finished oil-wet condition.

The differences in ultimate oil recoveries between dolomites and limestones may be related to the mineral composition of these rocks. While limestone is basically composed of $\mathrm{CaCO}_{3}$, the dolomite rocks have magnesium in the mineral structure $\left(\mathrm{MgCaCO}_{3}\right)$ resulting in a higher affinity to polar compounds which can be adsorbed in the aging. The presence of magnesium ions could alter the wetting properties in carbonate rocks (Graue et al. 1999), considering diffusion through the mineral structure and the bulk fluid.

\section{Oil recovery by spontaneous imbibition with carbonated water}

A new set of cores aged in for $2500 \mathrm{~h}$ was tested out for oil recoveries with spontaneous imbibition using seawater and formation water containing dissolved $\mathrm{CO}_{2}$. The device used in the tests was the specifically designed steel cell shown in Fig. 1b. The apparatus kept the brine and core pressurized, thus preventing separation of $\mathrm{CO}_{2}$ from the liquid phase. Each rock sample was placed in the steel cell and filled with the imbibing fluid (CWS or CFW) sitting in an oven at $64{ }^{\circ} \mathrm{C}$. As in the previous tests, oil recovery was monitored and recorded against time until an unresponsive state was secured.

Figure 6 depicts oil recovery from the limestone cores with CSW and CFW. In the case of CSW, oil cumulative

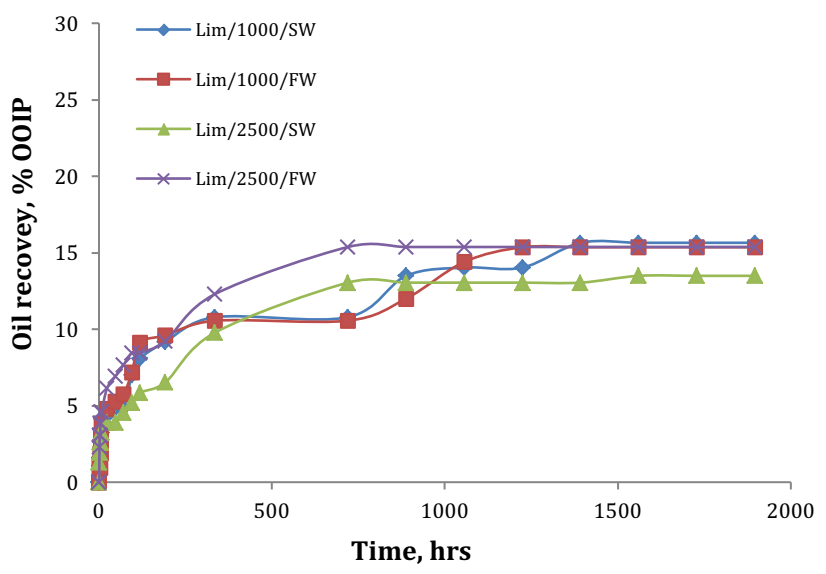

Fig. 4 Oil recovery from limestone samples aged for 1000 and $2500 \mathrm{~h}$

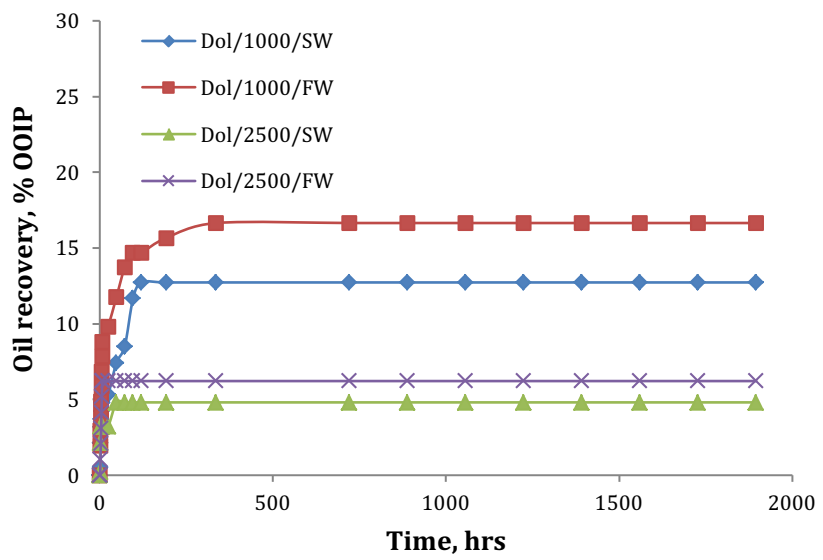

Fig. 5 Oil recovery from dolomite samples aged 1000 and $2500 \mathrm{~h}$

production reached $48 \%$ of OOIP. Besides the mechanism of wettability modification which may well be enhancing oil production, two other effects may be behind such high recovery efficiency: (1) the $\mathrm{CO}_{2}$ present in the seawater brine is transferred from the water to the oil phase, thus swelling the oil and at the same time reducing its viscosity, a combination that is known to favor additional oil recovery from the rock; (2) the mixing of $\mathrm{CO}_{2}$ and seawater generates the weak carbonic acid which reacts with calcite, the limestone main mineral, dissolving the rock and
Fig. 3 Adaptation in the coreholder for Amott-Harvey test with carbonated water, where $A$ casing coreholder, $B$ input diffuser with three injection lines, $B^{\prime}$ output diffuser with a single line, $C$ adaptation in coreholder, aluminum ring, $D$ rock sample

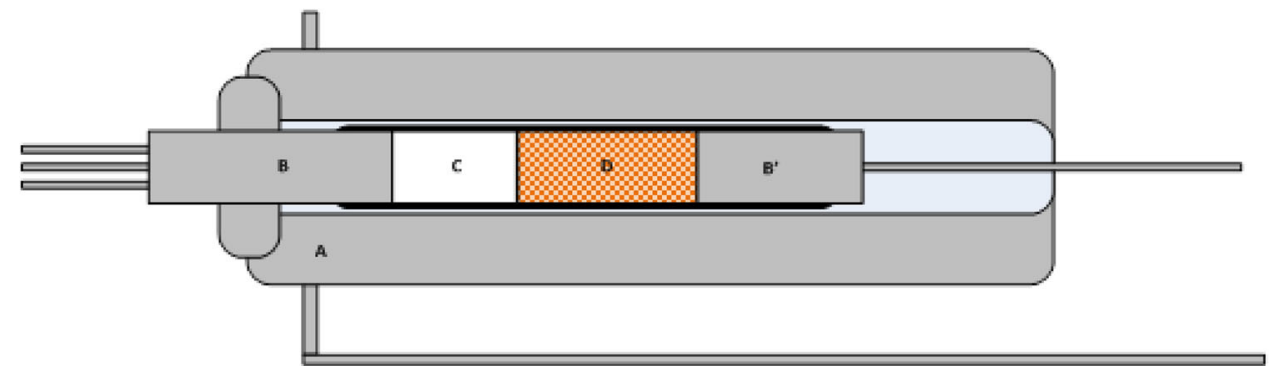




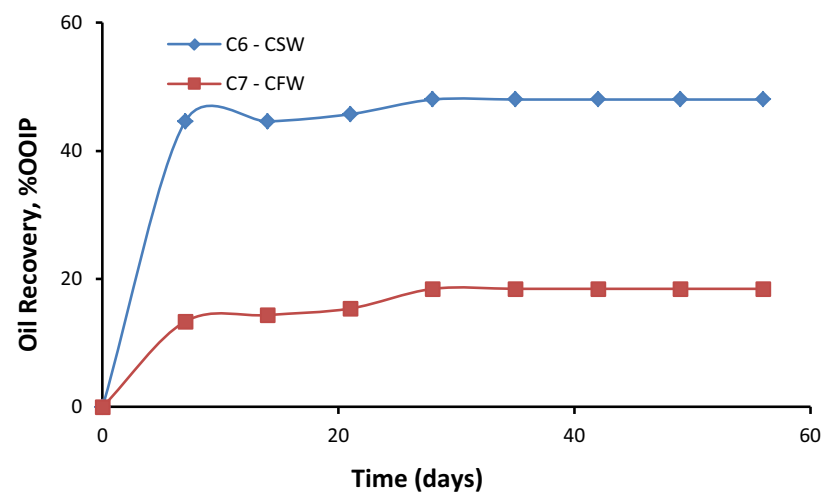

Fig. 6 Oil recovery from limestone cores with CSW and CFW at $64{ }^{\circ} \mathrm{C}$

altering its surface and flowing properties. Both effects are not strictly related to wettability alteration. In the case of spontaneous imbibition with CFW, the results in terms of oil recovery show much lower values than the ones with CSW. This is in line with the aforementioned effects, given the lower concentration of $\mathrm{CO}_{2}$ present in the saturated formation water. The high salinity formation brine only holds $0.4880 \%$ mass percent of $\mathrm{CO}_{2}$ while seawater can take up to $0.7826 \%$. The oil production results for limestone show two distinct trends in spontaneous imbibition. In the evaluation with CSW, the system acts as a water-wet system while with CFW the rock performs as neutral-wet. The results are in agreement with Rezaveisi et al. (2012). A comparison of the oil recovery obtained previously with the equivalent brines with no $\mathrm{CO}_{2}$, depicted in Fig. 4, points to a slight increase in recovery when $\mathrm{CO}_{2}$ is added to FW and a higher recovery when of the addition to SW.

The results obtained for the dolomite cores evaluated at the same conditions are shown in Fig. 7. The production curves show a moderate increase in recovery for both carbonated brines, with a slightly higher recovery for the seawater brine. The ultimate oil recoveries of around 25 and $20 \%$ of OOIP indicate that wettability may alter toward more neutral-wet conditions for both cores at the concentrations evaluated. The slower production rate indicates that production was driven by mechanisms other than the wettability change. Likewise for limestones, production was higher with CSW. But, for the dolomites, the effect of a higher concentration of $\mathrm{CO}_{2}$ was not so pronounced, which is aligned with the fact that dolomites are less prone to dissolution.

\section{Cumulative oil recovery by spontaneous imbibition}

After the first imbibition period, all imbibing brines were switched. Figure 8 shows the cumulative oil recovery following brine alternations for the dolomite rocks at the two

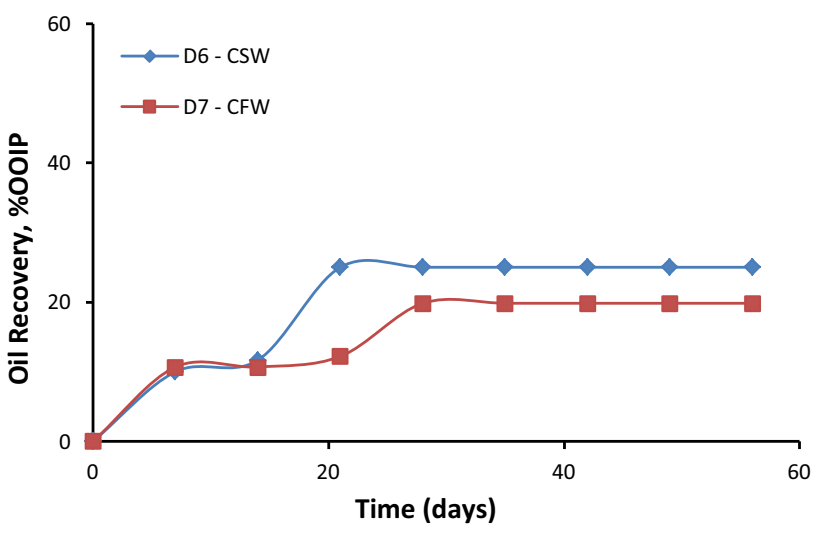

Fig. 7 Oil recovery of dolomite cores with CSW and CFW at $64{ }^{\circ} \mathrm{C}$

aging conditions. Production curves show that spontaneous imbibition re-started after each and almost every brine switch. Increases in oil recovery were observed in every condition evaluated. It is remarkable that the increase in recovery in all cores occurred independently of the brine concentration used as imbibition fluid. The literature reports similar results only for changes with brines with lower salt concentrations (Zhang and Austad 2006). The effect can be attributed to the formation of a salt gradient created between formation water and seawater concentration which allows diffusion of ions of the imbibing fluid up to the pores containing lower or higher salt concentrations; such gradient induces a new oil recovery process.

Wettability alteration in dolomite rocks appears to be more complex than other carbonates, such as chalk or limestone. The rock/brine/crude oil interaction can modify the adhesion forces guiding by capillary forces between rock surfaces and imbibing fluid turns the rock more waterwet (Liu et al. 2007). Also, possible dissolutions can alter the rock wetting properties, which leads to an additional oil recovery (Zhang and Austad 2006). It is important to mention that the same tests were carried out in limestone cores, as shown in Fig. 9, and they did not present additional oil recovery at the same conditions applied for the dolomite rocks. There can be many reasons for such difference; the most obvious is the difference in mineral composition between the two rocks studied.

\section{Wettability alteration by Amott-Harvey index $\left(I_{\mathbf{A} \_\mathbf{H}}\right)$}

After testing oil recovery with spontaneous imbibition, the cores were taken to the runs for the wettability Amott-Harvey index. Table 3 shows the Amott-Harvey indexes calculated for the limestone and dolomite cores using SW and $\mathrm{FW}$, and its corresponding brine switches. In each test, two brine switches were applied such that the tests finalized with 
Fig. 8 Oil recovery in dolomite samples aged 1000 and $2500 \mathrm{~h}$ and after switching brine concentrations

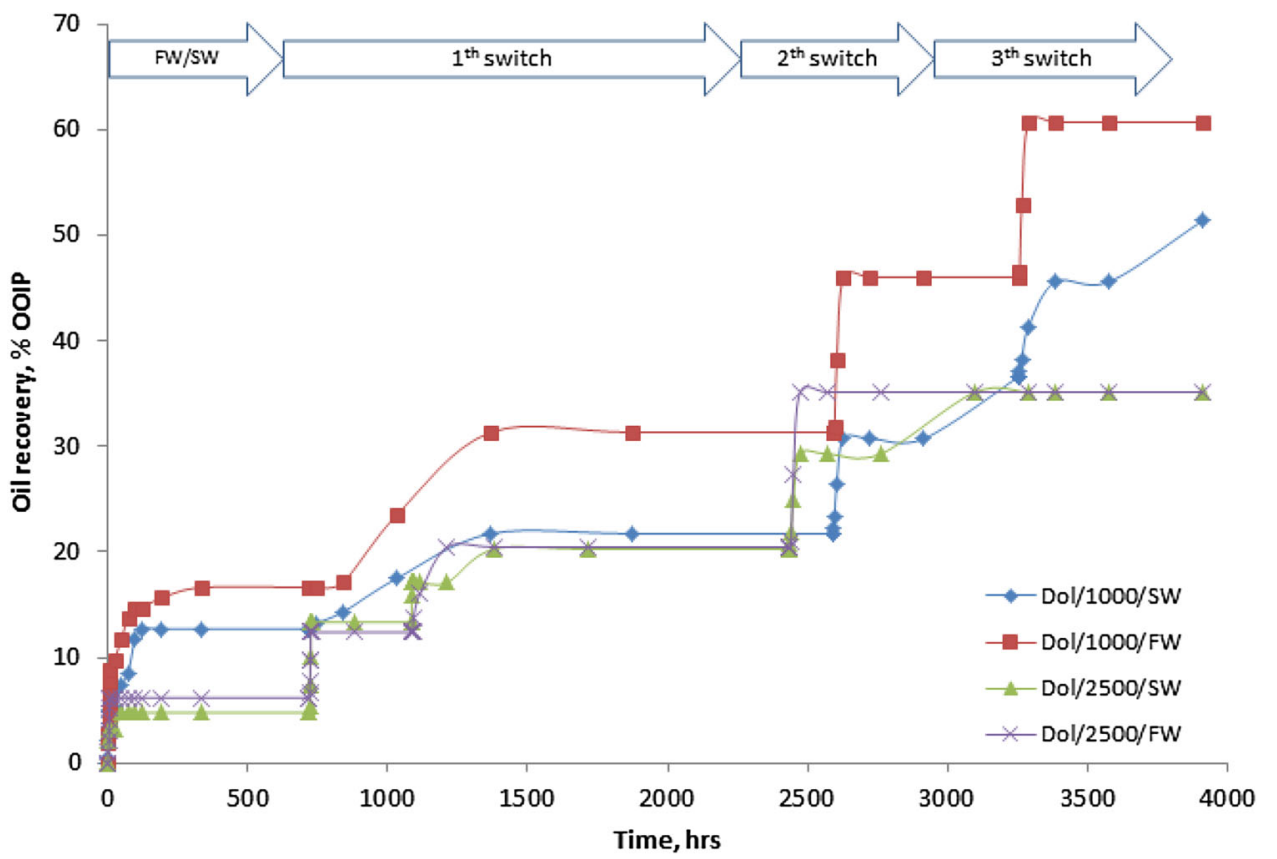

the same brine they started off. All initial indexes (round 1) refer to the evaluation of wettability right after rock aging, while indexes in rounds 2 and 3 refer to the evaluation after switching the brine. Results clearly show that the AmottHarvey wettability index increases with brine replacement in both carbonates independently of the initial brine.

The results displayed in Table 3 were also plotted in Figs. 10 and 11 for better visualization of the trends. Figure 10 depicts the results for the dolomites while Fig. 11 for the limestone. All rock samples tested departed from an initial oil-wet condition; the oil-wetting preference is more pronounced in the dolomites regardless of the similar aging process, pointing that dolomite is more prone to the adsorption of polar compounds during the aging process. Brine changes caused the rock to consistently become more water-wetting. The wettability alteration effect was more pronounced in the cases where the brine changes started out from SW. The index curve moved up toward the boundary between the neutral-wet and water-wet zones. For the tests starting with FW, the effects were less pronounced, but still the wettability index increased enough to reach the neutral-wetting zone. Figure 11 presented the results obtained with the limestone samples aged for $2500 \mathrm{~h}$. The graph shows that aging brought the rock cores to a slightly oil-wet condition. The processes of brine replacement promoted changes in rock wettability to the neutral-wetting state. As in the cases of dolomites, wettability alteration in the limestone runs does not depend on the brine concentration used in each steep, neither on the initial brine concentration.

\section{Wettability alteration in carbonates with $\mathrm{CO}_{2}$ dissolved in water}

Wettability alteration was studied also with the carbonated version of the brines for both limestone and dolomite samples. The wettability indexes were obtained by following the same procedure as in the previous tests. Table 4 shows the $I_{\mathrm{A} \mathrm{H}_{\mathrm{H}}}$ indexes calculated for limestones and dolomites after the tests with the carbonated brines and its corresponding switches. First, it is important to notice that the modification introduced into the coreholder worked properly and all steps in Amott-Harvey test procedure were performed properly, furnishing the necessary data for the calculation of the wettability index with carbonated water. The initial assessments of wettability (round 1) show the dolomites samples to depart from a preferably oilwetting condition in both cases $\left(I_{\mathrm{A} \_\mathrm{H}}=-0.4163\right.$ with $\mathrm{CSW}$ and $I_{\mathrm{A} \_\mathrm{H}}=-0.4552$ with $\mathrm{CFW}$ ), validating once again the aging procedure used for these rocks. The index values obtained for the limestone rocks show two initial wetting conditions. For the rock first evaluated with CSW, the $I_{\mathrm{A} \_\mathrm{H}}$ was -0.1373 indicating neutral wettability, while for the rock first evaluated with $\mathrm{CFW}$ the $I_{\mathrm{A} \_\mathrm{H}}$ was -0.6184 indicating a highly oil-wet condition.

Figures 12 and 13 depict the variation of the $I_{\mathrm{A}_{-} \mathrm{H}}$ indexes with the switch of the carbonated brines. Figure 12 shows a discreet alteration in wettability with carbonated brine replacement in the cases of dolomite. In both cases, the wettability changes moved the rock category from oilwet to neutral-wet. Also, the variations in the wettability

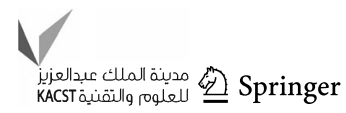


Fig. 9 Oil recovery in limestone samples aged 1000 and $2500 \mathrm{~h}$ and after switching brine concentrations

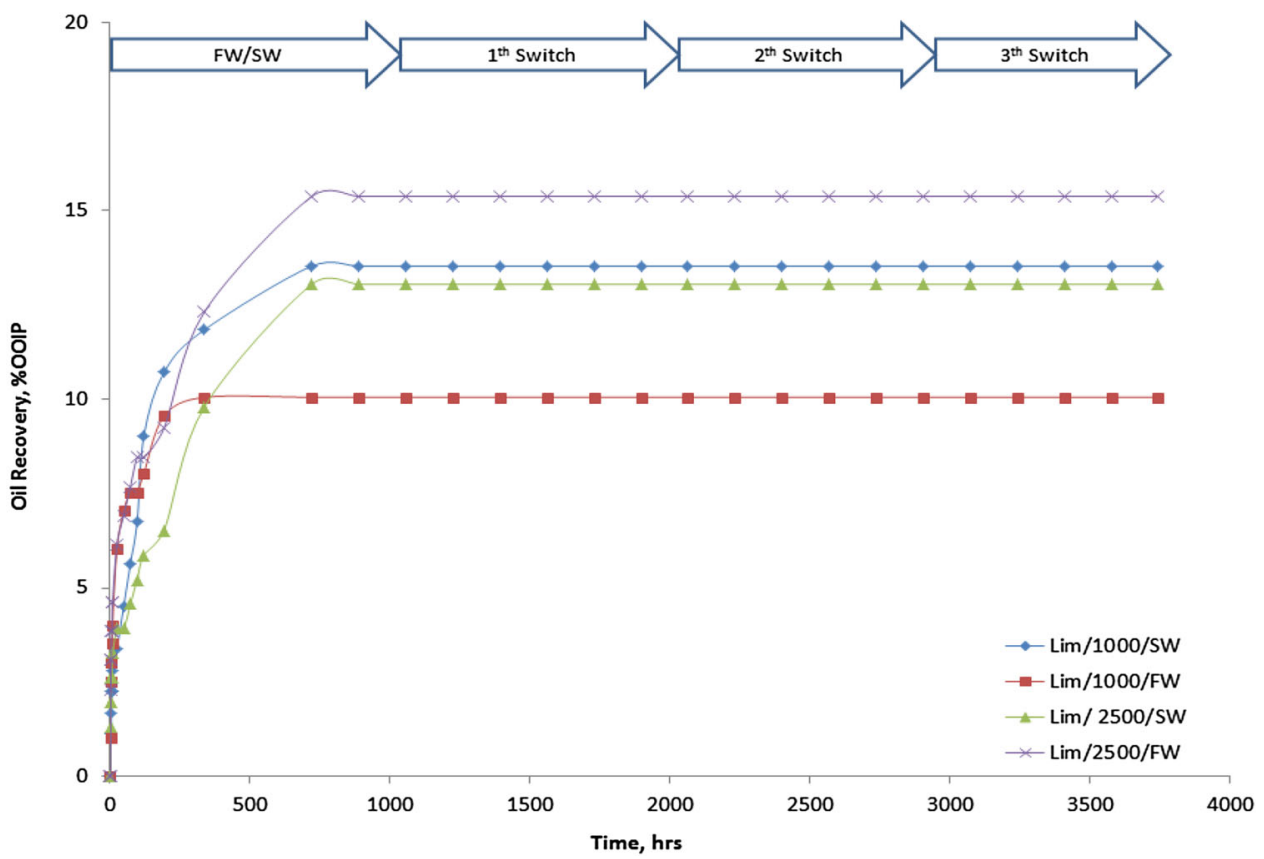

Table 3 Amott-Harvey wettability index $\left(I_{\mathrm{A}_{-} \mathrm{H}}\right)$ with seawater and formation water

\begin{tabular}{llllr}
\hline Rock type & & & Dolomite & Limestone \\
Brine concentration & Round & & & $I_{\text {A_H }}$ \\
\hline SW-FW-SW & 1 & -0.4583 & -0.3915 \\
& 2 & -0.228 & 0.151 \\
FW-SW-FW & 3 & 0.2821 & -0.0736 \\
& 1 & -0.4329 & -0.275 \\
& 2 & -0.3086 & 0.0232 \\
\hline
\end{tabular}

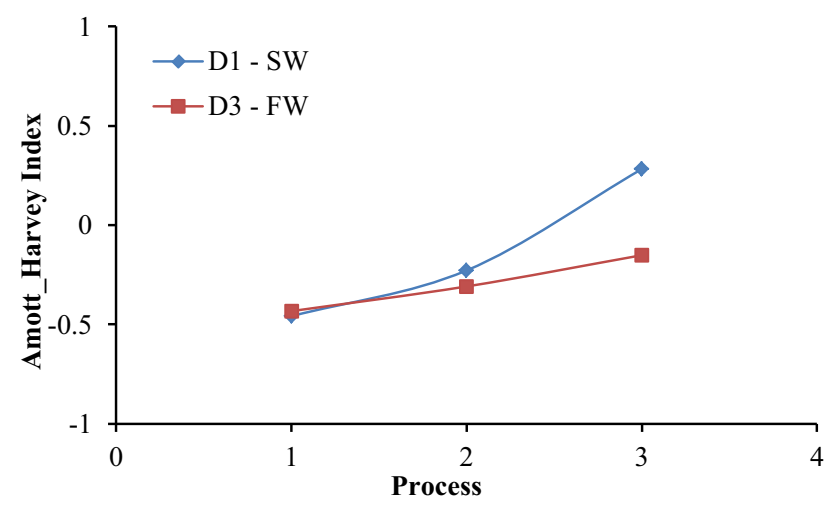

Fig. 10 Amott-Harvey wettability index for dolomites started with SW and FW

index were independent of the increase or decrease in the salinity of the brine used in each switch. The runs started with CFW present alterations that are slightly more



Fig. 11 Amott-Harvey wettability index for limestones started with SW and FW

pronounced. Also, from the comparison of the plots in Figs. 10 and 12, the wettability alteration observed for dolomites using carbonated brines, shown in Fig. 10, is less marked than with non-carbonated brines, depicted in 
Fig. 12. It is worth to remind that the chemical interaction of $\mathrm{CO}_{2}$ and the brine creates a low $\mathrm{pH}$ fluid which reacts with the basic rock matrix and therefore may affect the rock transport properties, an additional drive over the wettability alteration mechanism.

Figure 13 shows the wettability alteration trend for the limestone rocks evaluated at the same conditions as the dolomites. Although the changes in the indexes were small and not enough to alter the wettability condition from the original state, they present the same pattern seen in the tests with non-carbonated brines. The indexes consistently increased in the sequential change of brines, in both cases.

The effects on wettability alteration with the presence of $\mathrm{CO}_{2}$ dissolved in both brines can be depicted after comparing the plots in Figs. 11 and 13. The alterations rendered by the carbonated brines were smaller than by the brines without $\mathrm{CO}_{2}$. Likewise for the dolomite rocks, $\mathrm{CO}_{2}$ or its derived ions when dissolved in brine seem to inhibit the mechanism of wettability alteration when limestone rocks are subject to changes in brine salt concentrations. It is also important to mention that after the tests with carbonated brines, the limestone samples presented some visible dissolution on the surface, effect not perceived with the dolomite samples.

\section{Conclusion}

The spontaneous imbibition evaluation of dolomite rocks showed an additional oil recovery which can be directly associated with wettability alteration. Therefore, it is possible to link the brine concentration with those changes. Also, increments in recovery were non-dependent on the brine concentration applied. Limestone rocks did not present the same effects with brine replacement in spontaneous imbibition tests. The same result was obtained in the evaluation with carbonated water.

The Amott-Harvey wettability tests confirmed the wettability alteration in dolomite rocks when brines were injected at alternating concentrations. The wettability

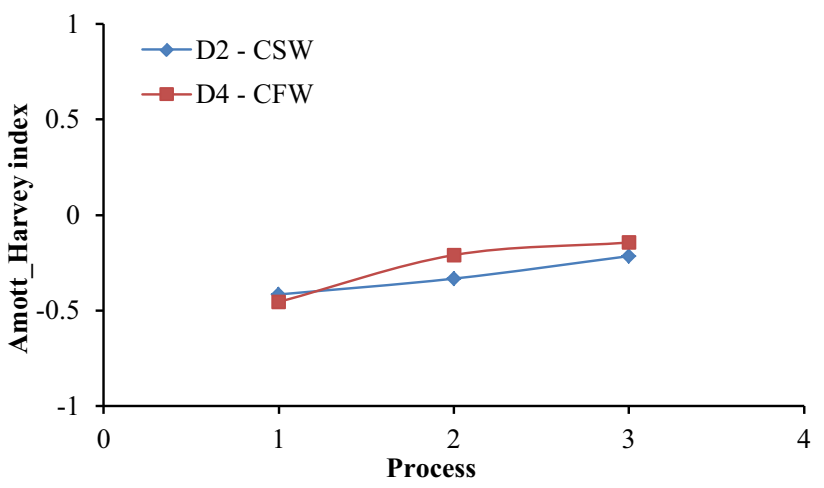

Fig. 12 Effect on Amott-Harvey wettability index for dolomites started with CSW and CFW

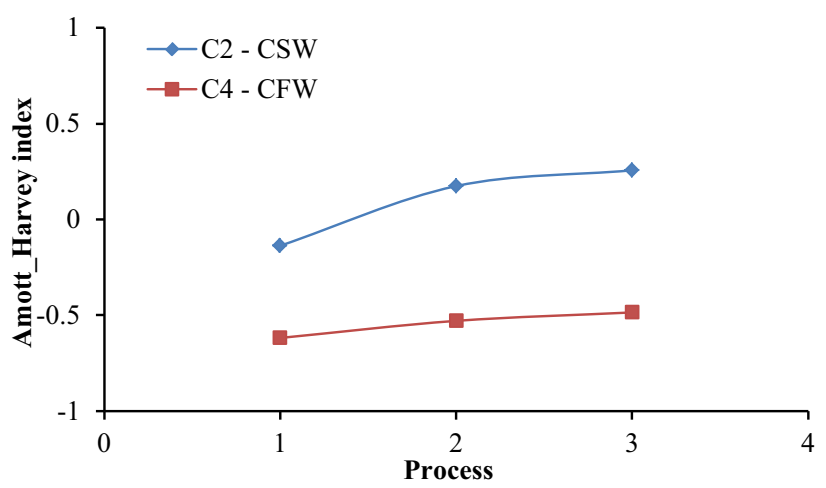

Fig. 13 Effect on the Amott-Harvey wettability index for limestones started with CSW and CFW

alteration was more pronounced in dolomites which had the switching brine process started out from seawater. For the limestone core, indexes also suggest wettability alteration to be non-dependent on the concentration change.

The Amott-Harvey wettability tests carried out with the equivalent carbonated brines show alteration in the wetting properties with the switching in the injected fluid. For dolomites and limestone indistinctly, wettability alteration occurred also for both water salinities turning the rock less oil-wet. However, the incremental production induced by carbonated brines was less pronounced than those by the

Table 4 Evaluation of Amott-Harvey wettability index $\left(I_{\mathrm{A} \_\mathrm{H}}\right)$ with carbonated water

\begin{tabular}{lllll}
\hline Rock type & & & Dolomite & Limestone \\
Brine concentration & Round & $I_{\mathrm{A} \_\mathrm{H}}$ & -0.6184 \\
\hline CSW-CFW-CSW & 1 & -0.4552 & -0.5292 \\
& 2 & -0.21 & -0.4852 \\
CFW-CSW-CFW & 3 & -0.1442 & -0.1373 \\
& 1 & -0.4163 & 0.1741 \\
& 2 & -0.3333 & 0.2564 \\
\hline
\end{tabular}


equivalent non-carbonated brines. $\mathrm{CO}_{2}$ or its derived ions dissolved in brine seem to inhibit the mechanism of wettability alteration when rocks were subject to switches in brine concentrations or to introduce opposing mechanisms associated to chemical interactions between the carbonated brine and the rock.

Acknowledgements The authors would like to acknowledge CAPES and PETROBRAS for the financial support to the research reported in the paper.

Open Access This article is distributed under the terms of the Creative Commons Attribution 4.0 International License (http:// creativecommons.org/licenses/by/4.0/), which permits unrestricted use, distribution, and reproduction in any medium, provided you give appropriate credit to the original author(s) and the source, provide a link to the Creative Commons license, and indicate if changes were made.

\section{References}

Al-Attar HH, Mahmoud MY, Zekri AY, Almehaideb RA, Ghannam MT (2013) Low salinity flooding in a selected carbonate reservoir: experimental approach. SPE 164788

Al-Maamari RSH, Buckley JS (2000) Asphaltene precipitation and alteration of wetting: can wettability change during oil production? SPE 59292

Alotaibi MB, Nars-El-Din HA (2009) Chemistry of injection water and its impact on oil recovery in carbonate and clastic formations. SPE 121565

Duan Z, Sun R (2003) An improved model calculating $\mathrm{CO}_{2}$ solubility in pure water and aqueous $\mathrm{NaCl}$ solutions from 273 to $533 \mathrm{~K}$ and from 0 to 2000 bar. Chem Geol 193:257-271

Fjelde I, Asen SM (2010) Wettability alteration during water flooding and carbon dioxide flooding of reservoir chalk rocks. SPE 130992
Graue A, Viksund BG, Eilertsen T, Moe R (1999) Systematic wettability alteration by aging sandstone and carbonate rock in crude oil. J Pet Sci Eng 24:85-97

Høgnesen EJ, Standnes DC, Austad T (2006) Experimental and numerical investigation of high temperature imbibition into preferential oil-wet chalk. J Pet Sci Eng 53:100-112

Karimaie H, Torsæter O, Esfahani MR, Dadashpour M, Hashemi SM (2006) Experimental investigation of oil recovery during water imbibition. J Pet Sci Eng 52:297-304

Kechut NI, Sohrabi M, Jamiolahmady M (2010) Tertiary oil recovery and $\mathrm{CO}_{2}$ sequestration by carbonated water injection (CWI). SPE 139667

Liu Q, Dong M, Asghari K, Tu Y (2007) Wettability alteration by magnesium ion binding in heavy oil/brine/chemical/sand systems-analysis of electrostatic forces. J Pet Sci Eng 59:147-156

Rezaveisi M, Ayatollahi S, Rostami B (2012) Experimental investigation of matrix wettability effects on water imbibition in fractured artificial porous media. J Pet Sci Eng 86-87:165-171

Schembre JM, Tang GQ, Kovscek AR (2006) Wettability alteration and oil recovery by water imbibition at elevated temperatures. J Pet Sci Eng 52:131-148

Shehata M, Alotaibi MB, Nasr-El-Din HA (2014) Waterflooding in carbonate reservoirs: does the salinity matter? SPE 170254-PA

Standnes DC, Austad T (2000) Wettability alteration in chalk preparation of core material and oil properties. J Pet Sci Eng $28: 111-121$

Strand S, Standnes DC, Austad T (2006) New wettability test for chalk based on chromatographic separation of $\mathrm{SCN}^{-}$and $\mathrm{SO}_{4}{ }^{2-}$. J Pet Sci Eng 52:187-197

Yousef AA, Ayirala SC (2014) A novel water ionic composition optimization technology for smart water flooding application in carbonate reservoirs. SPE 169052-MS

Zhang P, Austad T (2006) Wettability and oil recovery from carbonates: effects of temperature and potential determining ions. Colloids Surf A Physicochem Eng Asp 279:179-187

Zhang P, Tweheyo MT, Austad T (2007) Wettability alteration and improved oil recovery by spontaneous imbibition of seawater into chalk: impact of the potential determining ions $\mathrm{Ca}^{2+}, \mathrm{Mg}^{2+}$, and $\mathrm{SO}_{4}{ }^{2-}$. Colloids Surf A Physicochem Eng Asp 301:199-208 